\title{
SHEAR STRENGTH OF REINFORCED RECYCLED AGGREGATE CONCRETE BEAMS WITHOUT SHEAR REINFORCEMENTS
}

\author{
Won-Chang CHOI ${ }^{\mathrm{a}}$, Hyun-Do YUN ${ }^{\mathrm{b}}$ \\ ${ }^{a}$ Department of Architectural Engineering, Gachon University, Seongnam, \\ Gyeonggi-do, 461-701, Republic of Korea \\ ${ }^{b}$ Department of Architectural Engineering, Chungnam National University, \\ Daejeon, 34134, Republic of Korea
}

Received 01 Apr 2014; accepted 14 Jul 2014

\begin{abstract}
As the demand for sustainable construction materials has risen over recent years, researchers have conducted several studies to expand the practical application of recycled construction materials, such as recycled aggregate. The author's previous research shows the potential application of recycled aggregate over a broad range of structural member types. This paper continues the earlier work and investigates the shear behaviour of reinforced recycled aggregate concrete beams without shear reinforcement using findings from the author's previous research. The variables in the test program are replacement rate $(0 \%, 30 \%, 60 \%$, and $100 \%)$ of recycled aggregate and shear span-to-depth ratio $(2.0,2.5$, 3.0, 4.0, and 5.0). This work compares the experimental results with results obtained using current code equations found in American Concrete Institute (ACI) 318 (2014) and equations proposed in the literature. This research has found that the current code equations can adequately predict the shear strength of recycled coarse aggregate concrete beams and possibly can be applied for the use of recycled aggregate in structural elements.
\end{abstract}

Keywords: recycled coarse aggregate, reinforced concrete beams, shear strength, replacement level, recycled aggregate concrete, shear behaviour.

\section{Introduction}

Using recycled aggregate as a sustainable construction material can be accomplished through rigorous mix design and the quality control of the manufacturing process (Hanson 1986). Recycled aggregate concrete, which is used mainly for nonstructural elements, has the potential to be used in a broad range of structural member types. This potential application is based on the author's previous work that investigated structural behavior, such as behavior under flexure, compression, bonding, and shrinkage (Lee 2002; Lee, Yun 2007, 2012; Choi et al. 2012; Choi, Yan 2012, 2013; Kim, Yun 2013, 2014). As related research, this study investigates the shear behavior of reinforced concrete beams that contain recycled coarse aggregate and compares the experimental results to those obtained using existing design equations.

Current specifications do not address the design procedures that are required to determine the shear capacity of reinforced concrete beams that contain recycled aggregate. So, several researchers have investigated concrete beams with recycled aggregate in an attempt to extend the applicability of recycled aggregate concrete.
For example, Sogo et al. (2004) tested ten concrete beams with recycled coarse and fine aggregate to investigate the shear behavior of reinforced recycled concrete beams. Their study considered recycled coarse aggregate with $2.45 \sim 2.46 \mathrm{~g} / \mathrm{cm}^{3}$ density and 5.57 6.18 percent absorption, and recycled fine aggregate with $2.23 \sim 2.30 \mathrm{~g} / \mathrm{cm}^{3}$ density and $11.21 \sim 12.51 \%$ absorption. Their results indicate that the same cracking patterns and failure mode are found in reinforced concrete beams with recycled aggregate concrete as are found in reinforced concrete beams without recycled aggregate concrete. The shear strength values decreased with the inclusion of both recycled coarse aggregate and virgin fine aggregate.

Gonazalez-Fonteboa and Martinez-Abella (2007) tested eight concrete beams using 1) conventional concrete and 2) recycled coarse aggregate to investigate the shear behavior of recycled concrete beams. The beams were fabricated using different transverse reinforcement ratios. Recycled aggregate, with sizes ranging from $4 \mathrm{~mm}$ to $12 \mathrm{~mm}$ and $10 \mathrm{~mm}$ to $25 \mathrm{~mm}$, replaced 50 percent of the aggregate. The density and water absorption rates of the recycled coarse aggregate ranged from $2.35 \sim 2.37 \mathrm{~g} / \mathrm{cm}^{3}$ and

Corresponding author: Hyun-Do Yun

E-mail:wiseroad@cnu.ac.kr 
$4.82 \sim 4.59 \%$, respectively. Compressive strength was in the range of 37 41 MPa. Gonazalez-Fonteboa and Martinez-Abella (2007) noted little difference between the two types of concrete in the cracking analysis in terms of premature cracking and notable splitting cracks along the tension reinforcement. However, the shear strength values matched the predicted values obtained from all the code equations.

Choi et al. (2010) examined three factors that can affect the shear strength of recycled concrete: shear spanto-depth ratios ( $a / d=1.5,2.5$, and 3.25), longitudinal reinforcement ratios ( $\rho=0.35 \%, 0.83 \%$, and $1.16 \%$ ), and replacement ratios of recycled aggregate $(0 \%, 30 \%, 50 \%$, and $100 \%$ ). The specific gravity and the absorption of recycled aggregate were 2.48 and 1.93 , respectively. Choi et al. (2010) observed a decrease in the shear strength of the recycled concrete beams with an increase in the replacement rate using the recycled aggregate, and a decrease in the span-to-depth ratio. They found that recycled aggregate concrete using a 50\% or less recycled aggregate replacement rate is acceptable and can be applied in current design methods.

Other examples in the literature report that the current specifications that are used to predict the shear strength of reinforced concrete beams without shear reinforcement are applicable to structural components, and that recycled aggregate could possibly be used without any considerable decrease of shear strength (Sogo et al. 2004; Gonazalez-Fonteboa, Martinez-Abella 2007; Choi et al. 2010).

Meanwhile, researchers have conducted limited tests to support that a broad range of recycled aggregate types can be used in structural components and that laboratory-scale mixtures can help with the understanding of the shear behavior of reinforced concrete beams that contain recycled aggregate, the recommended use of recycled aggregate in shear members is limited due to the abrupt failure of such members. So, this study includes full-size specimens and ready-mixed concrete to investigate the shear behavior of reinforced concrete beams with recycled coarse aggregate for practical applications and compares the measured shear strength values and the predicted strength values in terms of several existing code provisions, as presented in Table 1.

The ACI 318 (2014) equations used to determine the shear strength of reinforced concrete beams incorporate the tensile strength of concrete $\left(\sqrt{ } f_{c}^{\prime}\right)$, crack control $\left(\rho_{w}\right)$, and the shear span-to-depth ratio $(a / d)$, as presented in Eqn (2) in Table 1. The ACI specifications also include
Table 1. Existing equations to determine shear strength of beams with no stirrups

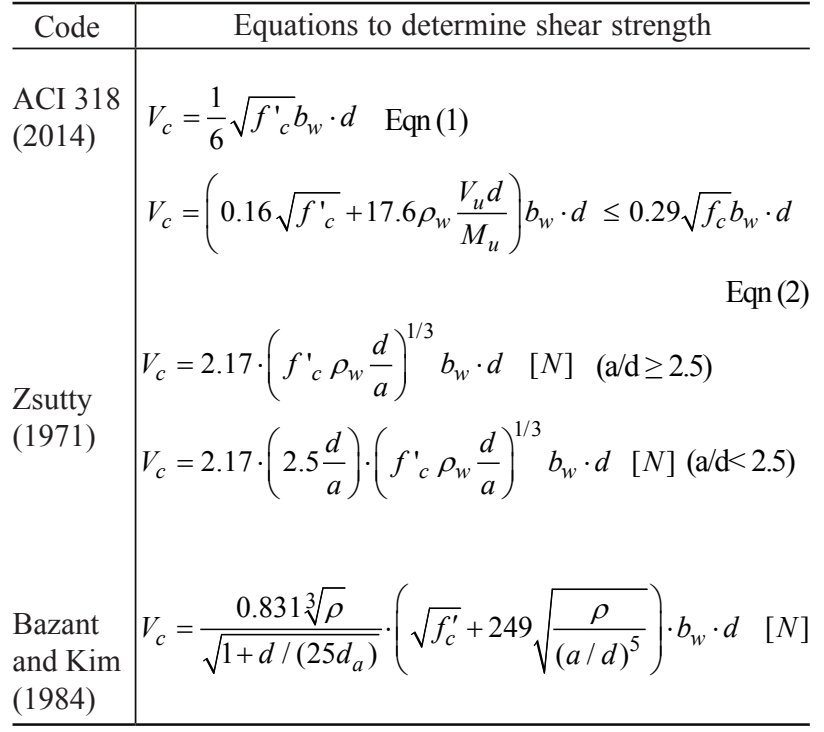

a simpler and more conservative equation (Eqn (1) in Table 1). However, the literature indicates that the ACI equations have shortcomings in predicting shear strength due to the different mechanisms that employ beam action and arch action, and that they do not include all the factors that affect each of the components of the shearresisting mechanisms and their interactions (Park, Paulay 1975). Therefore, this study also considers Zsutty's (1971) equation, which is derived using dimensional and statistical regression analyses, and the equation in Bazant and Kim (1984), which includes the factor of effective depth $(d)$ and maximum aggregate size $\left(d_{a}\right)$.

\section{Experimental program}

\subsection{Specimen preparation}

For this study, fourteen reinforced concrete beams with no shear reinforcement were fabricated in sections of $400 \times 600 \mathrm{~mm}$. The main variables in this research are the shear span-to-depth ratios $(a / d=2.0,2.5,3.0,4.0$ and $5.0)$ and the replacement rates of recycled coarse aggregate $(0 \%, 30 \%, 60 \%$ and $100 \%)$. Table 2 and Figure 1 provide details about the test specimens. Recycled coarse aggregate can be obtained from demolished concrete debris. In order to satisfy the minimum quality requirements for recycled aggregate, this study used recycled coarse aggregate with $2.99 \%$ absorption and $2.49 \mathrm{~g} / \mathrm{cm}^{3}$ dry unit weight. Details regarding the preparation and properties of the recycled coarse aggregate can be found in the

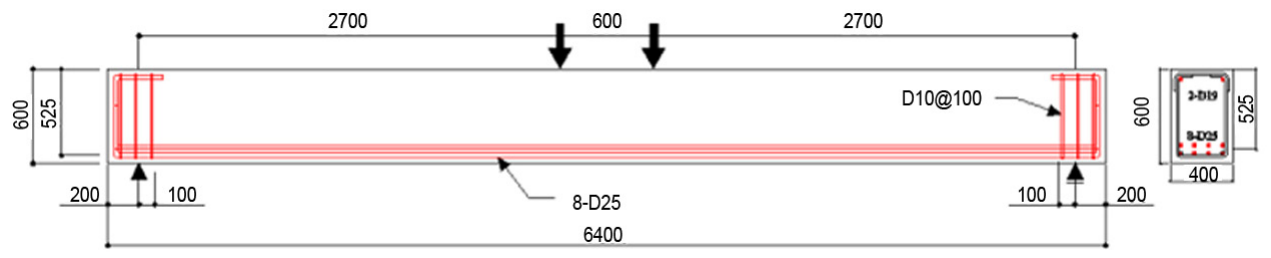

Fig. 1. Section dimensions $(\mathrm{a} / \mathrm{d}=5.0$, unit: $\mathrm{mm})$ 
Table 2. Test matrix for beam specimens

\begin{tabular}{|c|c|c|c|c|c|c|c|}
\hline Spcimens & $\begin{array}{l}b \times d \\
(\mathrm{~mm})\end{array}$ & $\begin{array}{c}l_{n} \\
(\mathrm{~mm})\end{array}$ & $\mathrm{a} / \mathrm{d}$ & $\begin{array}{c}f^{\prime}{ }^{\prime} \\
(\mathrm{MPa}) \\
\end{array}$ & $\begin{array}{c}\text { Longitudinal } \\
\text { reinforcement, } \rho_{w}\end{array}$ & $\begin{array}{c}\text { Replacement level } \\
(\%)\end{array}$ & $\begin{array}{l}\text { Number of } \\
\text { specimens }\end{array}$ \\
\hline $\begin{array}{l}\text { S-2.0-A100 } \\
\text { S-2.5-A100 } \\
\text { S-3.0-A100 } \\
\text { S-4.0-A100 } \\
\text { S-5.0-A0 } \\
\text { S-5.0-A30 } \\
\text { S-5.0-A60 } \\
\text { S-5.0-A100 }\end{array}$ & $400 \times 525$ & $\begin{array}{l}2,700 \\
\\
3,800 \\
4,900 \\
6,000\end{array}$ & $\begin{array}{c}2 \\
2.5 \\
3 \\
4 \\
5\end{array}$ & 27 & $\begin{array}{c}8-\mathrm{D} 25 \\
(0.0188)\end{array}$ & $\begin{array}{c}0 \\
30 \\
60 \\
100\end{array}$ & $\begin{array}{l}1 \\
2\end{array}$ \\
\hline
\end{tabular}

Table 3. Mix design for concrete

\begin{tabular}{|c|c|c|c|c|c|c|c|c|c|}
\hline \multirow{2}{*}{$\begin{array}{l}\text { Replacement level } \\
(\%)\end{array}$} & \multirow{2}{*}{$\begin{array}{c}f_{c}^{\prime} \\
(\mathrm{MPa})\end{array}$} & \multirow{2}{*}{$\begin{array}{l}\text { Slump } \\
(\mathrm{mm})\end{array}$} & \multirow{2}{*}{$\begin{array}{l}\mathrm{W} / \mathrm{C} \\
(\%)\end{array}$} & \multicolumn{6}{|c|}{ Unit weight $\left(\mathrm{kg} / \mathrm{m}^{3}\right)$} \\
\hline & & & & W & C & $\mathrm{S}$ & G & RG & $\mathrm{AD}$ \\
\hline 0 & \multirow{4}{*}{27} & \multirow{4}{*}{150} & \multirow{4}{*}{43.6} & \multirow{4}{*}{132} & \multirow{4}{*}{392} & 823 & 960 & 0 & \multirow{4}{*}{2.94} \\
\hline 30 & & & & & & & 672 & 267 & \\
\hline 60 & & & & & & & 394 & 533 & \\
\hline 100 & & & & & & 825 & 0 & 888 & \\
\hline
\end{tabular}

Note: $\mathrm{W}=$ water; $\mathrm{C}=$ cement; $\mathrm{S}=$ sand; $\mathrm{G}=$ gravel; $\mathrm{RG}=$ recycled coarse aggregate; and $\mathrm{AD}=$ admixture.

literature (Choi, Yun 2012). Detailed information regarding the specimen preparation and rigorous mix design are discussed elsewhere (Lee, Yun 2012). Table 3 shows the mix design for this study.

Table 4. Material properties of concrete

\begin{tabular}{c|c|c|c}
\hline $\begin{array}{c}\text { Replacement } \\
\text { level } \\
(\%)\end{array}$ & $\begin{array}{c}\text { Compressive } \\
\text { strength } \\
f_{c u} \\
(\mathrm{MPa})\end{array}$ & $\begin{array}{c}\text { Elastic } \\
\text { modulus } \\
E_{c} \\
(\mathrm{GPa})\end{array}$ & $\begin{array}{c}\text { Splitting tensile } \\
\text { strength } \\
f_{s p} \\
(\mathrm{MPa})\end{array}$ \\
\hline 0 & 37 & 25.8 & 3.5 \\
30 & 34 & 13.5 & 2.5 \\
60 & 32 & 13.4 & 3.1 \\
100 & 29 & 12.8 & 2.7 \\
\hline
\end{tabular}

The main reinforcement used in the specimens was D25 with a nominal diameter of $25 \mathrm{~mm}$. The yield strength of D25 was $433 \mathrm{MPa}$. The compressive design strength of the concrete was $27 \mathrm{MPa}$, and the material properties presented in Table 4 indicate that the compressive strength, splitting tensile strength, and elastic modulus values decreased as the replacement rate for the recycled aggregate increased. The authors derived similar results in related research (Lee, Yun 2007, 2012).

\subsection{Test procedure}

Figure 2 presents a schematic of the test setup. A fourpoint load using a hydraulic jack $(1000 \mathrm{kN})$ was applied with displacement control. For the S-2.5-100 specimen (span depth ratio of 2.5), a three-point load was applied to investigate the shear behavior in terms of loading condition. Displacement transducers were installed to monitor the displacement at the specified location, curvature, and deformation around the shear span. A dial gauge was installed diagonally between the support and loading point

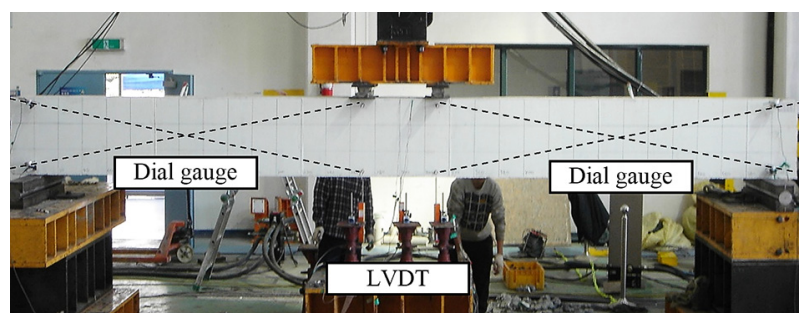

Fig. 2. Test set-up

in order to monitor the location of the initial and diagonal cracks.

\section{Results and discussion}

\subsection{Load-displacement behavior}

Figure 3 presents the load-displacement responses for each tested specimen. The figure shows that, generally, as the applied load increases, the deflection tends to increase linearly, which results in the elastic behavior of concrete and steel due to the small deformation. After the specimen cracks, the reduced moment of inertia causes a decrease in the slope of the load displacement relationship. Next, the nonlinear deformation increases as the applied load increases. Subsequently, diagonal shear failure occurs.

Figure 3(a) shows the load-displacement relationship with respect to the shear span-to-depth ratio. Similarly to the specimens contain $100 \%$ recycled coarse aggregate, the monitored cracking loads range from approximately 12 to $15 \%$ of the maximum load. However, the initial cracking loads of Specimens S2.5-A100 and S3-A100 are relatively higher than the others, and the available strength from the arch action does not allow any reduction in stiffness after diagonal cracks form in the beam 

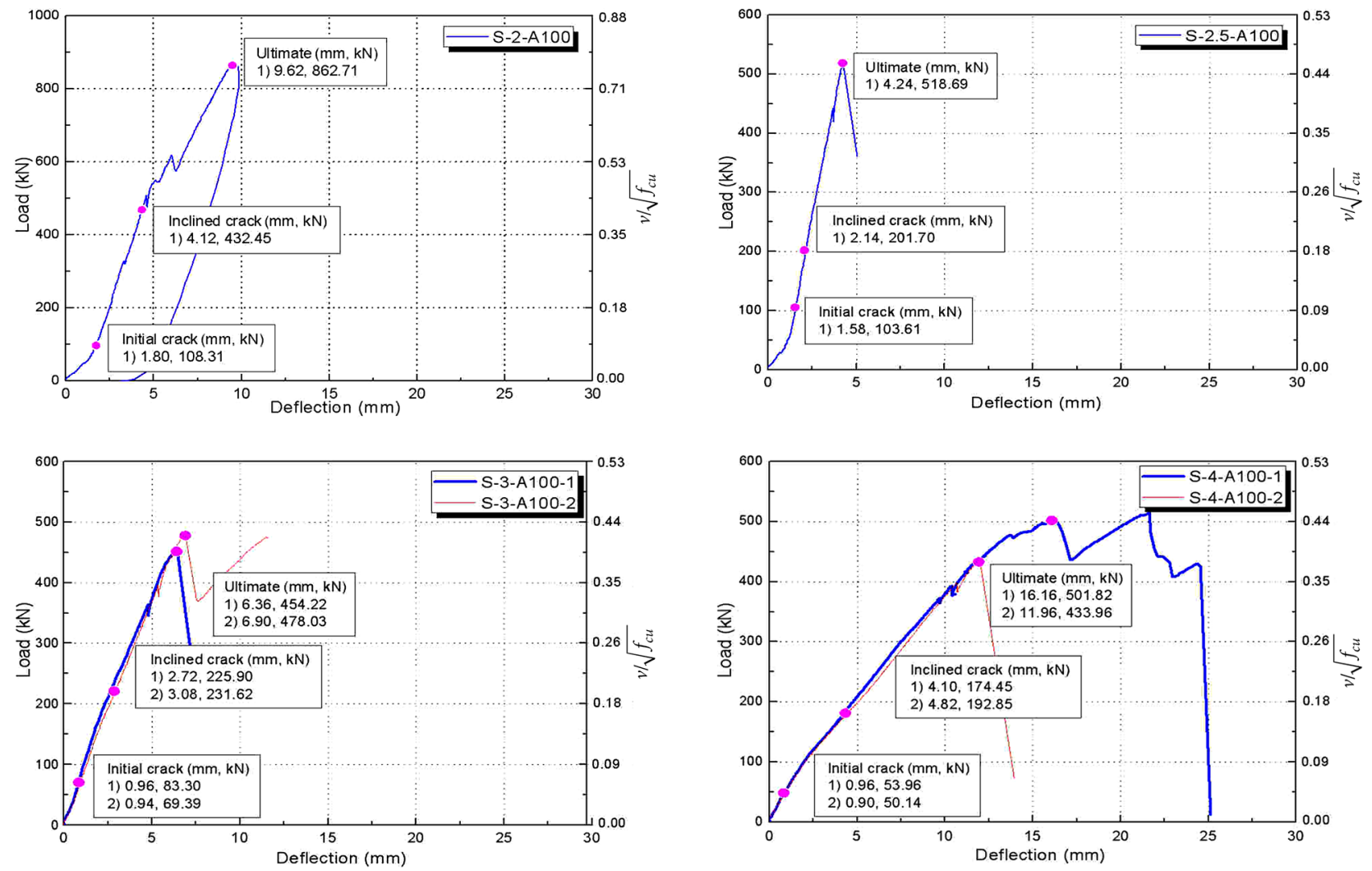

(a) Load displacement curves with various shear span-to-depth ratio (a/d)
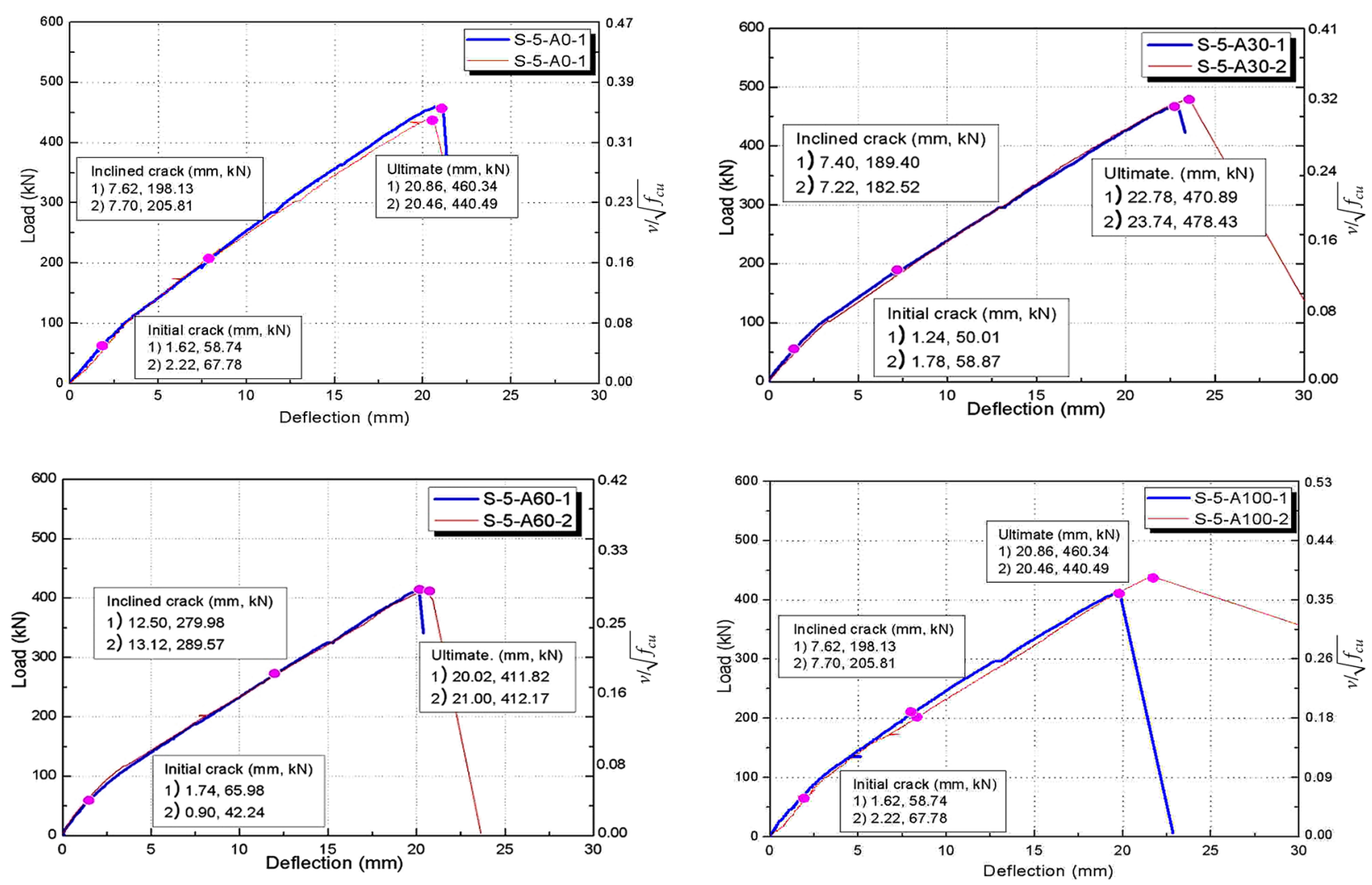

(b) Load displacement curve with recycled aggregate replacement ratio

Fig. 3. Load displacement curves 
Table 5. Summary of test results for beam specimens

\begin{tabular}{l|c|c|c|c|c|c|c|c|c|c|c}
\hline & \multicolumn{3}{|c|}{ Initial crack } & \multicolumn{3}{c|}{ Inclined crack } & \multicolumn{3}{c|}{ Max. load } & \multicolumn{2}{c}{$\begin{array}{c}\text { Reserved shear } \\
\text { strength }\end{array}$} \\
\cline { 2 - 11 } Specimens & $\begin{array}{c}\delta_{i} \\
(\mathrm{~mm})\end{array}$ & $\begin{array}{c}V_{i} \\
(\mathrm{kN})\end{array}$ & $\begin{array}{c}k_{i} \\
(\mathrm{kN} / \mathrm{mm})\end{array}$ & $\begin{array}{c}\delta_{c r} \\
(\mathrm{~mm})\end{array}$ & $\begin{array}{c}V_{c r} \\
(\mathrm{kN})\end{array}$ & $\begin{array}{c}k_{c r} \\
(\mathrm{kN} / \mathrm{mm})\end{array}$ & $\begin{array}{c}\delta_{c} \\
(\mathrm{~mm})\end{array}$ & $\begin{array}{c}V_{c} \\
(\mathrm{kN})\end{array}$ & $\begin{array}{c}k_{c} \\
(\mathrm{kN} / \mathrm{mm})\end{array}$ & $\begin{array}{c}V_{c}-V_{c r} \\
(\mathrm{kN})\end{array}$ & $V_{c} / V_{c r}$ \\
\hline S-2-A100 & 1.80 & 108.31 & 60.17 & 4.12 & 432.45 & 104.96 & 9.62 & 862.71 & 89.68 & 430.26 & 1.99 \\
S-2.5-A100 & 1.58 & 103.61 & 65.58 & 2.14 & 201.70 & 94.25 & 4.24 & 518.69 & 122.33 & 316.99 & 2.57 \\
S-3-A100-1 & 0.96 & 83.30 & 86.77 & 2.72 & 225.90 & 83.05 & 6.36 & 454.22 & 71.42 & 228.32 & 2.01 \\
S-3-A100-2 & 0.94 & 69.39 & 73.82 & 3.08 & 231.62 & 75.20 & 6.90 & 478.03 & 62.28 & 246.41 & 2.06 \\
S-4-A100-1 & 0.96 & 53.96 & 56.21 & 4.10 & 174.45 & 42.55 & 16.16 & 501.82 & 31.05 & 327.37 & 2.88 \\
S-4-A100-2 & 0.90 & 50.14 & 55.71 & 4.82 & 192.85 & 40.01 & 11.96 & 433.96 & 36.28 & 241.11 & 2.25 \\
S-5-A0-1 & 1.62 & 58.74 & 36.26 & 7.62 & 198.13 & 26.00 & 20.86 & 460.34 & 22.07 & 262.21 & 2.32 \\
S-5-A0-2 & 2.22 & 67.78 & 30.53 & 7.70 & 205.81 & 26.73 & 20.46 & 440.49 & 21.53 & 234.68 & 2.14 \\
S-5-A30-1 & 1.24 & 50.01 & 40.33 & 7.40 & 189.40 & 25.59 & 22.78 & 470.89 & 20.67 & 281.49 & 2.49 \\
S-5-A30-2 & 1.78 & 58.87 & 33.07 & 7.22 & 182.52 & 25.28 & 23.74 & 478.43 & 20.15 & 295.91 & 2.62 \\
S-5-A60-1 & 1.74 & 65.98 & 37.92 & 12.50 & 279.98 & 22.40 & 20.02 & 411.82 & 20.57 & 131.84 & 1.47 \\
S-5-A60-2 & 0.90 & 42.24 & 46.93 & 13.12 & 289.57 & 22.07 & 21.00 & 412.17 & 19.63 & 122.60 & 1.42 \\
S-5-A100-1 & 1.70 & 63.48 & 37.34 & 10.48 & 256.74 & 24.50 & 20.38 & 413.03 & 20.27 & 156.29 & 1.61 \\
S-5-A100-2 & 1.88 & 57.14 & 30.39 & 11.82 & 265.63 & 22.47 & 22.00 & 438.61 & 19.94 & 172.89 & 1.65 \\
\hline
\end{tabular}

due to the arch action in the beam when the shear spanto-depth ratio is less than 2.5. Meanwhile, as the shear span-to-depth ratio increases, the beam action in the shear span controls the capacity of the beam. The formation of dowel cracks and secondary diagonal cracks near the longitudinal reinforcement are evident, particularly in the specimens with a shear span-to-depth ratio of 5.0.

Figure 3(b) shows the load-displacement relationship of the specimens in terms of the replacement rate for recycled aggregate with a constant shear span-todepth ratio of 5.0. Similarly to the specimens without recycled aggregate, the cracks initiate in the range of 10 to $15 \%$ maximum load. The occurrence of diagonal tension cracks is delayed as the replacement rate with recycled coarse aggregate increases. The maximum strength value also decreases as the replacement rate increases, which may be the result of the different types of recycled aggregate interlock in the beam.

Table 5 presents a summary of the diagonal cracking strength, ultimate strength, and reserved shear strength for each tested specimen.

\subsection{Crack propagation and failure mode}

Figure 4 presents the crack propagation pattern and failure mode for each specimen with respect to the shear span-to-depth ratio. After the flexural cracks initiate in the midspan of the specimens, flexural cracks in the shear span and/or in the effective depth from the supports propagate and subsequently become diagonal cracks with a $45^{\circ}$ angle. The propagation of the diagonal cracks along with the stress redistribution and crack width are evident instead of sudden failure after the initial diagonal crack formed when the shear span-to-depth ratio is less than 2.5.

When the shear span-to-depth ratio is greater than 3.0, the flexural cracks are transmitted to diagonal cracks; splitting cracks also are evident. In particular, Specimen S-5-A100 shows brittle failure with a radical reduction of strength after the maximum strength is reached. In

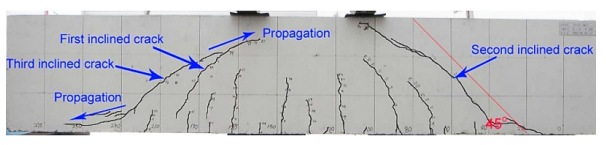

(a) S-2-A100

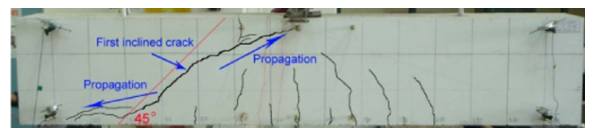

(b) S-2.5-A100

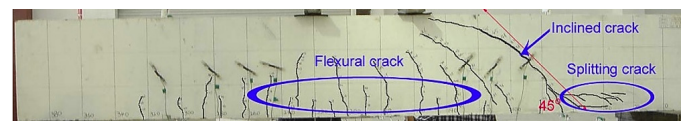

(c) S-3-A100

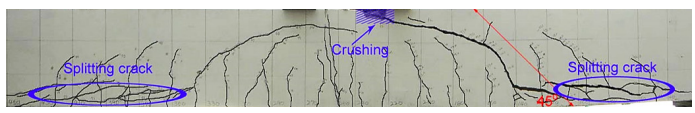

(d) S-4-A100

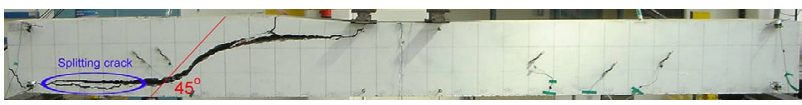

(e) S-5-A100

Fig. 4. Crack patterns with respect to shear span-to-depth ratio

addition, a substantial diagonal shear crack width (over $50 \mathrm{~mm}$ ) was measured at failure. The propagation of an inclined crack reduces the compression zone significantly after the failure of the beam action. A diagonal crack occurs when the available area of concrete is in the region of the load point. The compression area becomes too small to resist the compression force and then it crushes the beam as shear compression failure. Beams S-2-A100, S-2.5-100, S-4-A100 are good examples of such failure. These results agree well with the existing shear transfer mechanism results. 


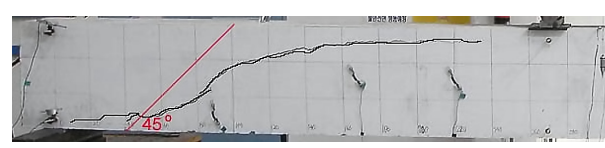

(a) S-5-A0

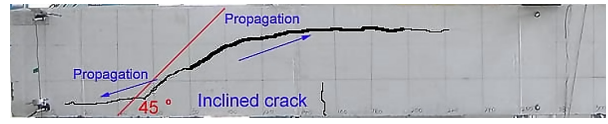

(b) S-5-A30

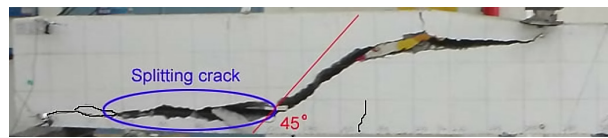

(c) S-5-A60

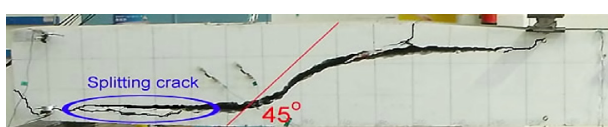

(d) S-5-A100

Fig. 5. Crack patterns with respect to replacement rate with recycled aggregate

Figure 5 shows crack propagations with respect to the replacement rate of recycled aggregate. As mentioned above, the formation of dowel cracks and secondary diagonal cracks near the longitudinal reinforcement are visible, particularly in all specimens with a shear span-to-depth ratio of 5.0.

Diagonal tension failure was observed. A similar cracking pattern each other is evident to the specimens in Figure 5, except for the crack width. As seen in Figure 5(d), cracks over $50 \mathrm{~mm}$ wide are evident with an increase in the replacement rate of recycled aggregate.

\subsection{Effects of tensile strength $\left(\sqrt{f^{\prime}}{ }_{c}\right)$ on the shear strength}

Figure 6 presents a comparison of the shear strength values of the beams that contain various types of aggregate, including lightweight aggregate, recycled aggregate, and natural aggregate, as plotted against the shear spanto-depth ratio (Lee, Yun 2012). The normalized shear

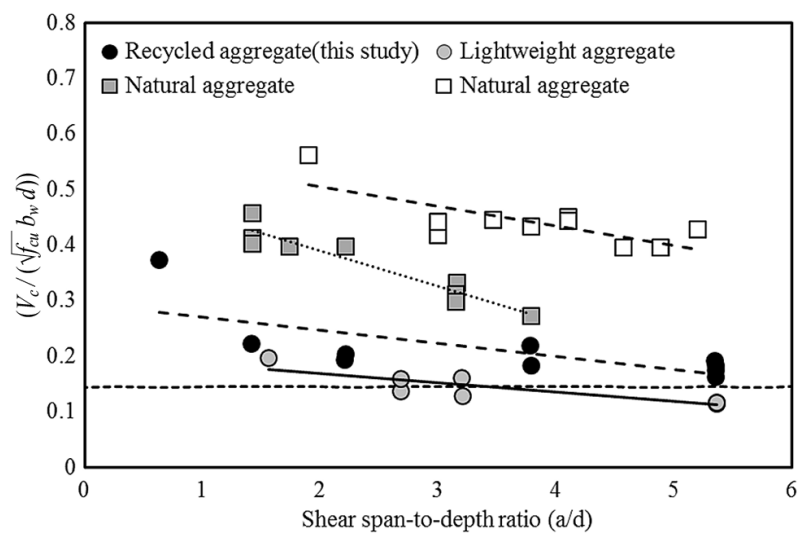

Fig. 6. Shear strength in terms of aggregate type (Lee, Yun 2007) strength $\left(V_{c} /\left(\sqrt{ } f^{\prime}{ }_{c} b_{w} d\right)\right)$ values were used to account for the tensile strength and sectional dimensions of the specimens. The shear strength of the reinforced concrete beam with lightweight aggregate can be computed using the coefficient $(\lambda)$ to account for the lower tensile strength of the lightweight concrete (ACI 318 2014). The shear strength value of the beam with recycled aggregate is higher than that with lightweight aggregate but lower than that with natural aggregate. That is, the tensile strength of the recycled concrete is less than that of conventional concrete. Overall, the experimental results show similar trends.

\subsection{Effects of reinforcement ratio $\left(\rho_{w}\right)$ on shear strength}

It is known that shear failure can occur in a typical reinforced concrete beam with natural aggregate with a reinforcement ratio in the range of $0.0075 \sim 0.025$, depending on the material properties and geometric characteristics of the reinforcement. In a reinforced concrete beam with a low reinforcement ratio, larger flexural cracks occur in the tension surface, with substantial propagation of cracks into the compression zone.

This study considers the reinforcement ratio of 0.0019 , and Figure 7 presents a comparison of the effects of the tension reinforcement ratio versus ultimate shear stress between the experimental results from this study and a previous related study (Choi et al. 2010; Lee, Yun 2012; Zu 2000; Baek et al. 2013). The study results are 5 40\% higher than the predicted values obtained from the ACI 318 Eqn (1) when the $a / d$ is less than 2.5. In addition, the experimental results show comparable shear strength values in the reinforced concrete beam using a similar reinforcement ratio, regardless of whether the beam is composed of natural aggregate or recycled aggregate. No considerable decrease in shear strength is evident when using recycled aggregate.

\subsection{Effects of shear span-to depth ratio on shear strength}

Figure 8 indicates that the ultimate flexural moment and the shear strength values of reinforced concrete beams

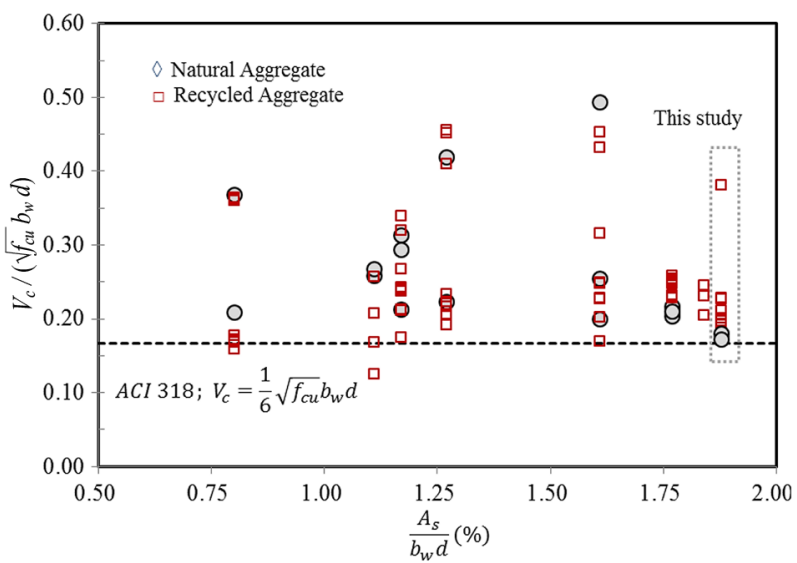

Fig. 7. Effect of longitudinal reinforcement ratio on ultimate shear strength 


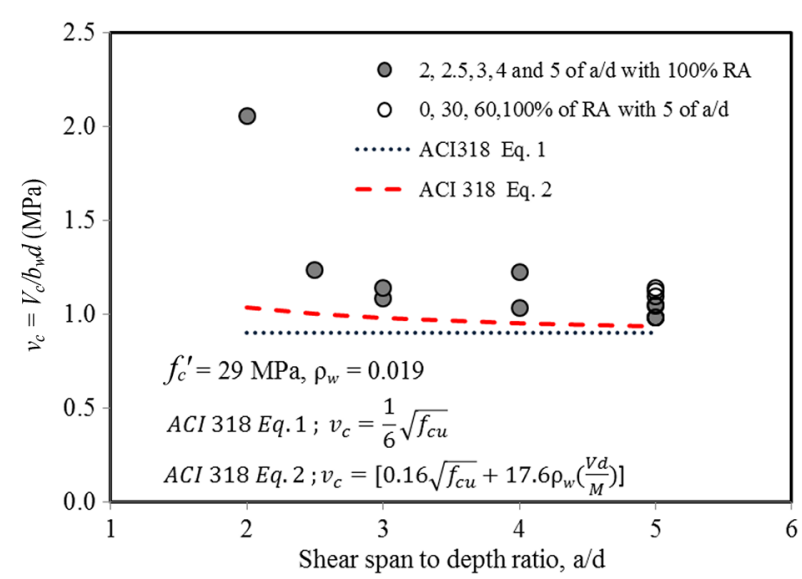

(a) Shear stress

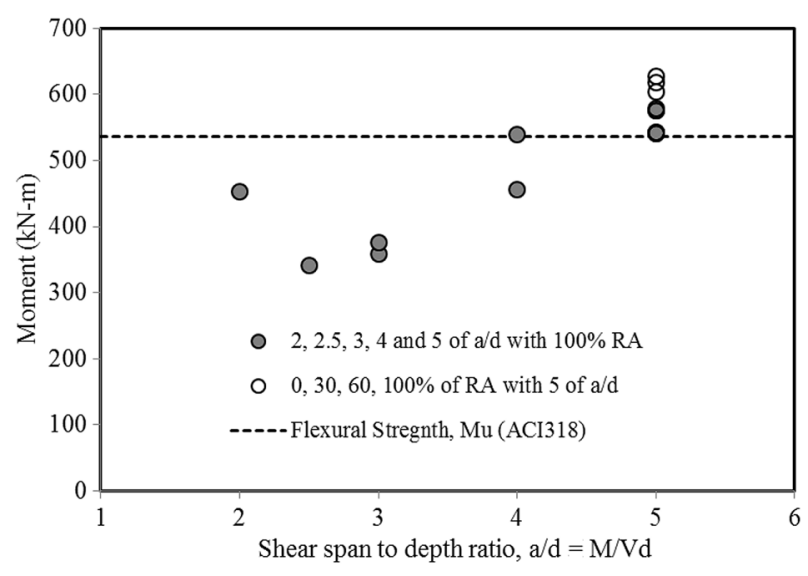

(b) Moment

Fig. 8. Moments and shears at failure with respect to shear span-to-depth ratio

with recycled concrete decrease as the shear span-todepth ratio increases. This occurrence is due to the beam action in the shear span as the shear span-to-depth ratio increases. Figure 8 also shows that the shear strength values of all the specimens in this study are higher than the predicted results obtained using the ACI 318 (2014) code provisions. In the case of the beam with a shear span-todepth ratio of 2.5 , the shear strength values are 10 20\% higher than the predicted values obtained using the ACI 318 (2014) equations. For a typical reinforced concrete beam with natural aggregate, the flexural capacity of the beam is not attained when the shear span-to-depth ratio is less than 5.0. As intended, the shear governs the strength of the beam. A reinforced concrete beam without shear reinforcement would fail abruptly once diagonal cracks appear in the critical section. The diagonal cracks and the moment at failure can be identified using the shear strain in the shear span. Figure 9 shows the shear strain values during the test. Regardless of the replacement rate for recycled aggregate, similar shear strain levels were measured, except for Specimen S-5-A100. After diagonal cracks formed, high shear strain levels were measured for Specimen S-5-A100. This result can be matched well in the failure mode with wide crack width.

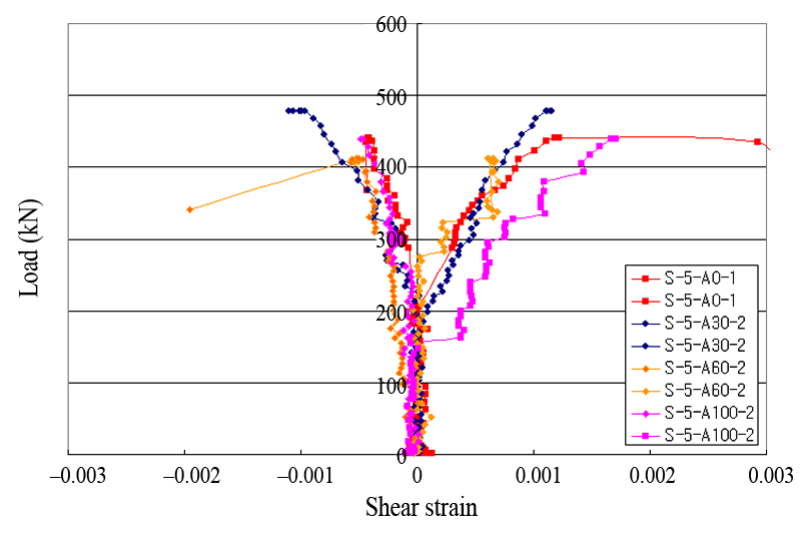

Fig. 9. Shear force versus shear strain

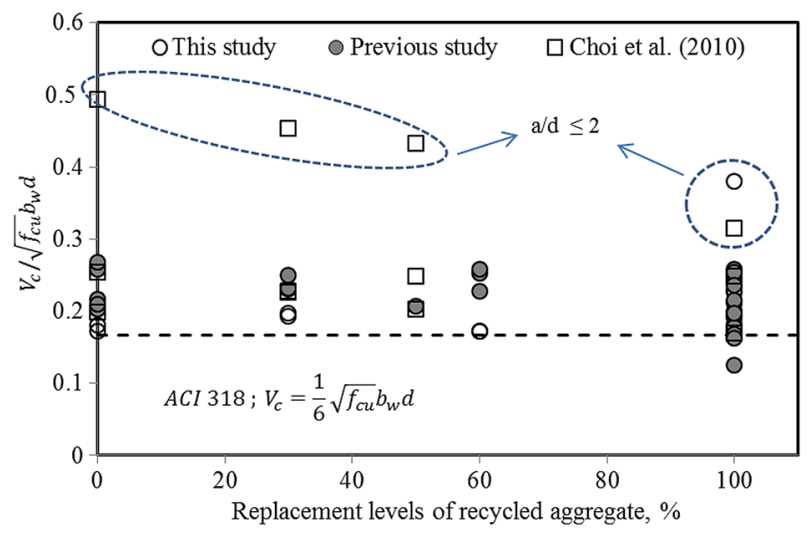

Fig. 10. Shear stress with respect to replacement levels of recycled aggregate

\subsection{Comparison with current specifications}

Figure 10 compares the current specification equation results to the experimental results obtained from related research and previous research found in the literature. The figure shows that the shear strength values are normalized by the section dimensions and compressive strength. Figure 10 also indicates that when the shear span-to-depth ratio is less than or equal to 2.0, the shear strength value tends to decrease as the replacement rate increases. Overall, the shear strength values throughout the experimental tests are higher than the predicted values obtained from the equations in ACI 318 (2014), regardless of the replacement rate with recycled aggregate.

As mentioned earlier, this study considers four existing equations in the literature (ACI 318 2014; Zsutty 1971; Bazant, Kim 1984) to verify the feasibility of using these equations to compute the shear strength of reinforced concrete beams with recycled aggregate in Figure 11.

Based on the results from the literature and this study, the current equations found in ACI 318 (2014) that are used to determine shear strength $\left(V_{c}\right)$ can conservatively predict, except the specimen with a shear spanto-depth ratio that is less than or equal to 2.0. When the span to depth ratio is less than 2.0, the computed results 


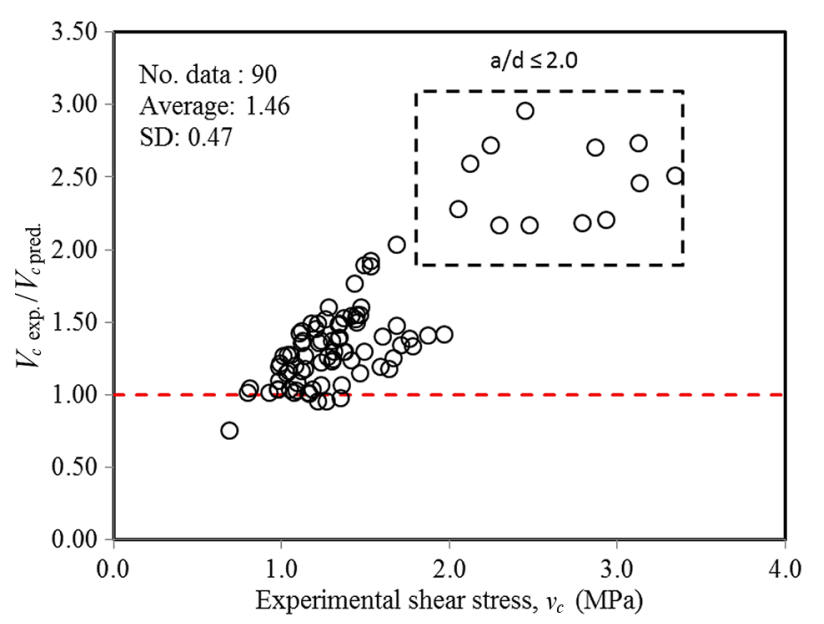

(a) ACI $318-$ Eq (1)

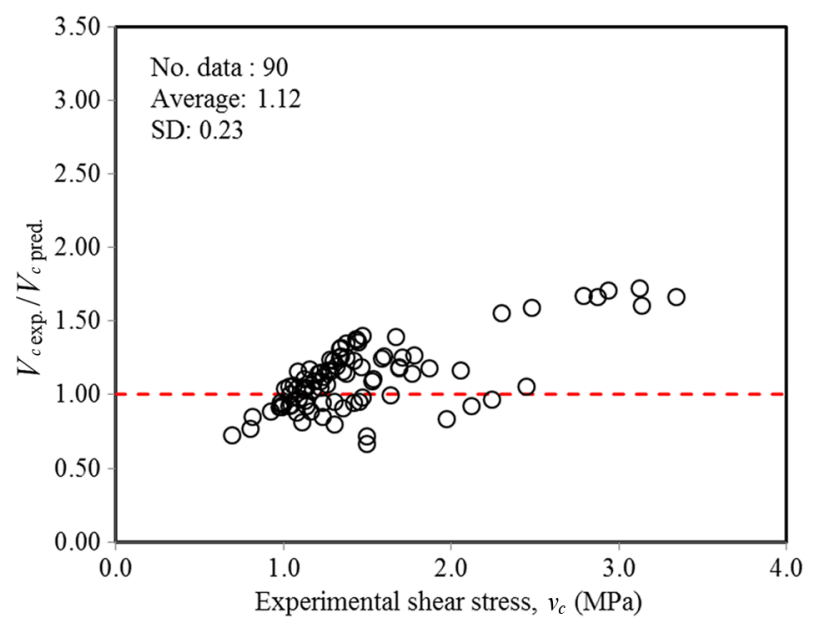

(c) Zsutty (1971)

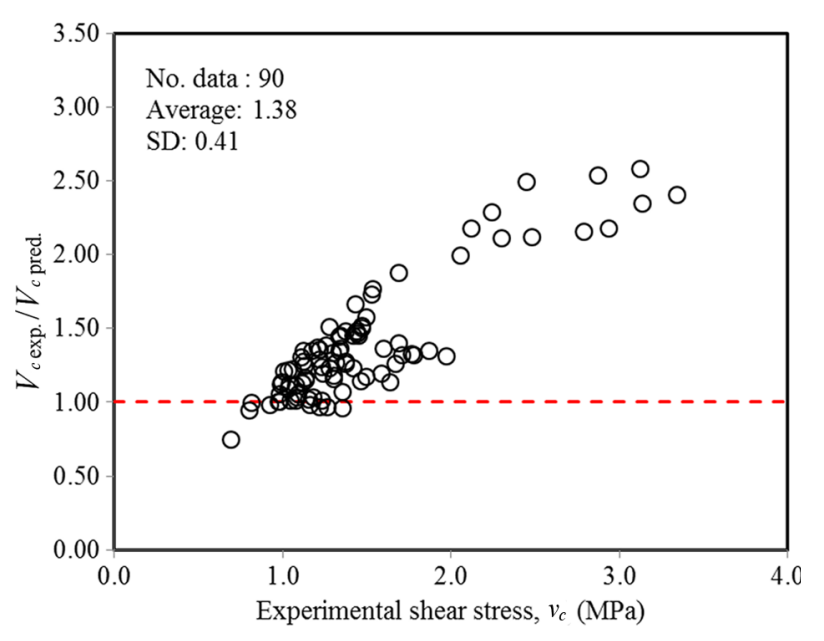

(b) ACI $318-$ Eq (2)

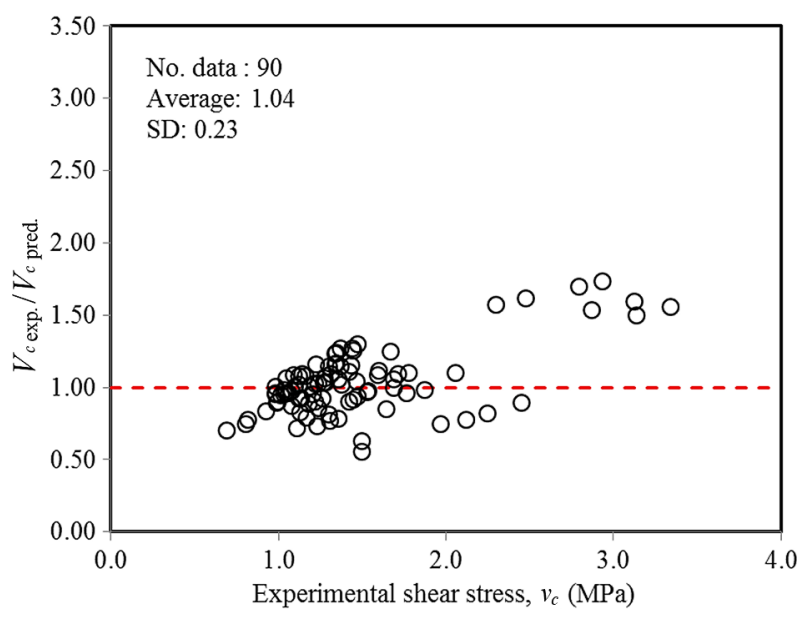

(d) Bazant and Kim (1984)

Fig. 11. Comparisons between experimental results and predicted values with existing equations

are excessively conservative. The Zsutty's (1971) equation and Bazant and Kim (1984) equation tend to underestimates the experimental results. Based on this study's results and results found in the literature, it seems feasible that the ACI 318 (2014) equations can be applied to predict shear strength of recycled aggregate concrete members.

\section{Conclusions}

1. Fourteen reinforced concrete beams without shear reinforcement and $100 \%$ recycled coarse aggregate were tested in this study to investigate shear behavior and to extend the applicability of the existing code equations to recycled aggregate concrete members. The variables used for the tests were concrete compressive strength values and shear span-to-depth ratios. The following conclusions can be drawn from the test results.
2. The shear behavior (including load deflection, deflection shape, shear deformation, failure mode, and shear strength) of beams composed with $100 \%$ recycled aggregate is similar to that of reinforced concrete beams with natural coarse aggregate.

3. The failure mode of reinforced concrete beams, even with $100 \%$ recycled aggregate, agrees well with the existing shear transfer mechanism.

The shear strength values of reinforced concrete beams with $100 \%$ recycled aggregate are higher than the design strength values used in the existing equations, regardless of the shear span-to-depth ratio. As a conservative design approach, the current specification equations in ACI 318 (2014) could be used to determine the shear strength of recycled aggregate concrete beams. For more precise predictions, however, the equations that include the shear span-to-depth ratio as a factor need to be revised when the shear span-to-depth ratio is less than or equal to 2.0. 


\section{References}

ACI 318. Building code requirements for structural concrete and commentary. American Concrete Institute. Farmington Hills, MI., 2014. 520 p.

Baek, S. M.; Kim, W. S.; Kang, H. K.; Kwak, Y. K. 2013. An experimental assessment on shear behavior of high strength recycled coarse aggregate concrete beams, Journal of the Architectural Institute of Korea 29(4): 27-36.

Bazant, Z. P.; Kim, J. K. 1984. Size effect in shear failure of longitudinally reinforced beams, ACI Journal 81(8): 456468.

Choi, H. B.; Yi, C. K.; Cho, H. H.; Kang, K. I. 2010. Experimental study on the shear strength of recycled aggregate concrete beams, Magazine of Concrete Research 62(2): 103-114. http://dx.doi.org/10.1680/macr.2008.62.2.103

Choi, W. C.; Yun, H. D.; Seo, S. Y. 2012. Flexural performance of reinforced recycled aggregate concrete beam, Magazine of Concrete Research 64(9): 955-960. http://dx.doi.org/10.1680/macr.11.00018

Choi, W. C.; Yun, H. D. 2012. Compressive behavior of reinforced concrete columns with recycled aggregate under uniaxial loading, Engineering Structures 41: 373-384. http://dx.doi.org/10.1016/j.engstruct.2012.03.037

Choi, W. C.; Yun, H. D. 2013. Long-term deflection and flexural behavior of reinforced concrete beams with recycled aggregate, Materials and Design 51: 742-750. http://dx.doi.org/10.1016/j.matdes.2013.04.044

Gonazalez-Fonteboa, B.; Martinez-Abella, F. 2007. Shear strength of recycled concrete beams, Construction and Building Materials 21(4): 887-893.

http://dx.doi.org/10.1016/j.conbuildmat.2005.12.018

Hanson, T. C. 1986. Recycled aggregates and recycled aggregate concrete second state-of-the-art report developments 1945-1985, Materials and Structures 19(3): 201-246. http://dx.doi.org/10.1007/BF02472036
Kim, S. W.; Yun, H. D. 2013. Influence of recycled coarse aggregates on the bond behavior of deformed bars in concrete, Engineering Structures 48: 133-143. http://dx.doi.org/10.1016/j.engstruct.2012.10.009

Kim, S. W.; Yun, H. D. 2014. Evaluation of the bond behavior of steel reinforcing bars in recycled fine aggregate concrete, Cement and Concrete Composites 46: 8-18. http://dx.doi.org/10.1016/j.cemconcomp.2013.10.013

Lee, K. H. 2002. Shear and flexural behavior of reinforced highstrength recycled-aggregate concrete beams: Master thesis. Chungnam National University, Republic of Korea. $64 \mathrm{p}$.

Lee, W. S.; Yun, H. D. 2007. Shear performance of reinforced recycled aggregate concrete beams, Journal of the Architectural Institute of Korea 23(4): 19-26.

Lee, Y. O.; Yun, H. D. 2012. Shear performance of full-scale recycled fine aggregate concrete beams without shear reinforcement, Journal of the Korea Concrete Institute 24(3): 225-232. http://dx.doi.org/10.4334/JKCI.2012.24.3.225

Park, R.; Paulay, T. 1975. Reinforced concrete structure. Wiley and Sons. 800 p. http://dx.doi.org/10.1002/9780470172834

Sogo, M.; Sogabe, T.; Maruyama, I.; Sato, R.; Kawai, K. 2004. Shear behavior of reinforced recycled concrete beams, in Proceedings of the International RILEM Conference, 2004, Barcelona, Spain, 610-618.

Zsutty, T. C. 1971. Shear strength prediction for separate categories of simple beam test, ACI Journal 68(2): 138-143.

$\mathrm{Zu}$, B. C. 2000. Characteristics of the flexural and shear behavior of reinforced concrete beams using recycled aggregate: Master thesis. Chungbuk National University, Republic of Korea. 65 p.

Won-Chang CHOI. Assistant Professor of Architectural Engineering Department at Gachon University, Seongnam-si, Korea. His research interests include development and application of high performance construction materials; health monitoring with nondestructive method in infrastructure; large-scale laboratory test.

Hyun-Do YUN. Professor of architectural engineering at Chungnam National University, Daejeon, Korea. His research interests include the structural application of high performance and sustainable materials for infrastructures, seismic retrofit technique for non-ductile buildings, and seismic performance evaluation. 